\title{
UNMANNED AERIAL VEHICLES IN THE PROTECTION OF THE ELEMENTS OF A COUNTRY'S CRITICAL INFRASTRUCTURE - SELECTED DIRECTIONS OF DEVELOPMENT
}

\author{
Lt. Col. Radosław BIELAWSKI, PhD Eng. \\ War Studies University \\ Faculty of National Security \\ r.bielawski@akademia.mil.pl
}

Witold RZĄDKOWSKI, PhD Eng.

Faculty of Power and Aeronautical Engineering

Warsaw University of Technology

Rafat PERZ, PhD Eng.

Faculty of Power and Aeronautical Engineering

Warsaw University of Technology

\begin{abstract}
This paper explores the directions for the application of unmanned aerial vehicles in the provision of security to vital elements of a country's critical infrastructure. The analysis focuses on two paths of development: the first one refers to the transportation system, the latter is related to the gas supply network - the basic components of a country's critical infrastructure. The first section of this paper will examine the current state of knowledge in the field, and is designed as a reference of terminology pertaining to unmanned aerial vehicles (definitions and classification). The section shall furthermore provide a basis for and a contribution to the developed conceptual-semantic framework for UAV research. The first direction of development is described in terms of the characteristics and assumptions of the system; this includes an overview of the specific requirements of the unmanned platform itself, as well as the elements of the system, such as a local monitoring centre and other components. Furthermore, this section provides the overview of the designated mobile application, whose development is expected to improve the efficiency of system operation, which is a conceptual novelty considering similar developments. The second


direction concerns the development of an unmanned system of production, storage, and use of chemical and radioactive substances, including pipelines for hazardous substances. The programme that fits perfectly in the framework of the second considered branch of development is "Cricket" [Polish: "Świerszcz"] - a programme implemented in the periodic inspection of gas supply infrastructure. The description of the programme in question included specifying the technical and operational requirements for the fight devices as well as for the equipment.

Keywords: security, critical infrastructure, unmanned aerial system/vehicle (UAS/UAV), programme "Świerszcz" [English: "Cricket"]

\section{Introduction}

The key features of unmanned aerial vehicles, such as relatively low production cost, low technical support costs, long flight time with no need for intermediate landing and high maximum altitude, contribute to their growing popularity as a solution for monitoring and detecting diverse types of threats. Among the recently developed applications of this type of aerial vehicles are applications that monitor traffic incidents and gas conduit networks.

Attempting to select and define the directions of development, it is essential to underline the fact that both the transportation system and the gas supply constitute elements of every country's critical infrastructure (CI), which can be defined as a system of interconnected functional objects, such as buildings, facilities, installations and services of key importance to the security of the state and its citizens; furthermore, the infrastructure is to ensure the efficient functioning of public administration authorities, institutions and enterprises. Critical infrastructure includes: energy, energy resources and fuel supply, communication systems, teleinformation networks, financial systems, food supply systems, water supply systems, health protection systems, transportation systems, rescue systems, as well as systems ensuring the continuity of public administration activities, systems of production, storing and use of chemical and radioactive substances, including pipelines for hazardous substances. The provision of protection to critical infrastructure may be understood as any measures aiming to ensure the functionality, continuity of operation and integrity of critical infrastructure to prevent threats, risks or weaknesses, as well as limiting and neutralising the 
effects of system failure or breakdown and its immediate reconstruction in the event of a breakdown, attacks and other events disturbing its proper functioning (National Critical Infrastructure Protection Programme 2015, pp. 4-6).

The analysis that follows deals with, on the one hand, the transportation and communication systems, and secondly, with the gas supply conduit system, focusing on production, storage and use of chemicals and radioactive substances (Emergency Management Act 2007). It is crucial to highlight the fact that these systems determine the existence and proper functioning of a state, while all the negative outcomes may result in the disruption of its proper functioning; hence, the protection of a country's critical infrastructure constitutes a priority task. In their essence, the tasks related to critical infrastructure go beyond ensuring a proper level of protection against diverse threats, and should embrace handling potential damage or disruption of its functioning at a possibly shortest time, ensuring that if these do happen, they are relatively easy to remove and do not cause additional losses for citizens and the economy.

The subject of scientific analysis taken up in this paper concerns the applicability of unmanned aerial vehicles in the provision of security to a country's critical infrastructure. The aim of the publication is to present directions of development of unmanned aerial systems through development of conceptual projects. The theoretical (cognitive) aim adapted herein is to systematise theoretical knowledge - terminology and classifications related to UAV.

\section{Terminology and classifications related to unmanned aerial vehicles}

When taking up the subject of unmanned aerial vehicles, it is vital to overview the subject literature so as to present and systematise terminology related to this particular type of aerial vehicle.

In contemporary terminology, any aircraft capable of multiple flights without any crew or passengers on board is referred to as an unmanned aerial vehicle. This type of aerial vehicle is considered as an element of an unmanned aerial system (UAS). It is a complete system, which comprises the unmanned aerial vehicle 
itself, a ground control system, and any auxiliary equipment included therein. An unmanned aerial vehicle can therefore be understood as a central element of an unmanned aerial system.

Another definition of an unmanned aerial vehicle can be found in the NATO terminology. It is understood as: a powered aerial vehicle that can usually be recoverable, which uses aerodynamic forces to provide vehicle lift. It can be piloted remotely and can carry a lethal or non-lethal payload. (AAP-6 2011, p. 386).

In the field of unmanned aerial vehicles, we can also see a tendency for building constructions which can be used both as manned and unmanned platforms. They are referred to as optionally piloted vehicles (OPV). A UAV flying device operated via remote radio control by a ground-based human operator is called a remotely piloted vehicle (RPV). Some of these machines are equipped with an autopilot function that takes over the control of a flight, with an exception of a take-off and landing phase. However, modern UAVs are capable of autonomous flights, which is possible by implementation of a system of tools for programming and executing the flight plan, together with pre-defined take-off, navigation, and landing manoeuvres, installed on their on-board computers (Sawicki 2012, p. 365).

In contemporary colloquial language, unmanned aerial vehicles are often referred to as drones. However, this term is not recommended and should be replaced by a proper technical nomenclature (Bielawski 2015, p. 79), which encompasses such terminology as: an unmanned aerial vehicle, an unmanned aerial system, an unmanned aerial platform, and their synonymous conjugations.

Unmanned aerial vehicles come in a variety of designs, which determine their basic flight parameters, such as: range, altitude, and endurance. Taking into account the above specifications, UAVs have been divided into classes and categories, as shown in the tables below (Tables 1-2). 


\begin{tabular}{|l|l|l|l|}
\hline Class & Category & Altitude $[\mathbf{m}]$ & Range $[\mathbf{k m}]$ \\
\hline \multirow{2}{*}{$\begin{array}{l}\text { Class I } \\
\downarrow 150 \mathrm{~kg})\end{array}$} & Small & $\downarrow 366$ & 50 \\
\cline { 2 - 4 } & Mini & $\downarrow 305$ & 25 \\
\cline { 2 - 4 } & Micro & $\downarrow 60$ & 5 \\
\hline $\begin{array}{l}\text { Class II } \\
(150 \div 600 \mathrm{~kg})\end{array}$ & Tactical & $\downarrow 915$ & 200 \\
\hline $\begin{array}{l}\text { Class III } \\
(\uparrow 600 \mathrm{~kg})\end{array}$ & HALE $^{1}$ & $\downarrow 19812$ & infinite \\
\cline { 2 - 4 } & MALE $^{2}$ & $\downarrow 12192$ & infinite \\
\hline
\end{tabular}

${ }^{1}$ High Altitude Long Endurance

${ }^{2}$ Medium Altitude Long Endurance

Table 1. Classification of Unmanned Aerial Vehicles acc. to the General Staff of the Polish Armed Forces (Przekwas and Jaroszuk 2009, p. 12)

\begin{tabular}{|l|l|l|l|l|}
\hline Category & Designation & Altitude $[\mathbf{m}]$ & $\begin{array}{l}\text { Range } \\
{[\mathbf{k m}]}\end{array}$ & $\begin{array}{l}\text { Flight } \\
\text { endurance } \\
{[\mathbf{h}]}\end{array}$ \\
\hline Tactical UAV & \multicolumn{5}{|l|}{} \\
\hline Micro & Micro & 250 & $\downarrow 10$ & 1 \\
\hline Mini & Mini & 350 & $\downarrow 10$ & $\downarrow 2$ \\
\hline Close range & Close Range (CR) & 3000 & $10 \div 30$ & $3 \div 6$ \\
\hline Short range & Short Range (SR) & 3000 & $30 \div 70$ & $3 \div 6$ \\
\hline Medium range & Medium Range (MR) & $3000 \div 5000$ & $70 \div 200$ & $6 \div 10$ \\
\hline $\begin{array}{l}\text { Medium range, high flight } \\
\text { endurance }\end{array}$ & MR Endurance (MRE) & $5000 \div 8000$ & $\uparrow 500$ & $10 \div 18$ \\
\hline $\begin{array}{l}\text { Low altitude, deep } \\
\text { penetration }\end{array}$ & $\begin{array}{l}\text { Low Altitude Deep } \\
\text { Penetration (LADP) }\end{array}$ & $50 \div 9000$ & $\uparrow 250$ & $0,5 \div 10$ \\
\hline $\begin{array}{l}\text { Low altitude, high flight } \\
\text { endurance }\end{array}$ & $\begin{array}{l}\text { Low Altitude Endurance } \\
\text { (LAE) }\end{array}$ & 3000 & $\uparrow 500$ & $\uparrow 24$ \\
\hline $\begin{array}{l}\text { Medium altitude, high flight } \\
\text { endurance }\end{array}$ & $\begin{array}{l}\text { Medium Altitude Long } \\
\text { Endurance (MALE) }\end{array}$ & $5000 \div 8000$ & $\uparrow 500$ & $24 \div 48$ \\
\hline Strategic UAV & \multicolumn{5}{|l|}{} & \multicolumn{2}{|l|}{} \\
\hline $\begin{array}{l}\text { High altitude, high flight } \\
\text { endurance }\end{array}$ & $\begin{array}{l}\text { High Altitude Long } \\
\text { Endurance }\end{array}$ & $\begin{array}{l}15000 \div \\
20000\end{array}$ & $\uparrow 1000$ & $24 \div 48$ \\
\hline $\begin{array}{l}\text { Unmanned combat Aerial } \\
\text { Vehicles }\end{array}$ & $\begin{array}{l}\text { Unmanned Combat } \\
\text { Aerial Vehicle (UCAV) }\end{array}$ & $\uparrow 20000$ & 400 & 2 \\
\hline
\end{tabular}

Table 2. Classification of Unmanned Aerial Vehicles acc. to scholars from the Military University of Technology (Zalewski 2001, p. 64) 


\section{UAVs in road accident rescue}

The versatile capabilities of UAVs may find application in road accident rescue. Unmanned platforms soaring in the skies provide a considerably better perspective than the view from the roadside. This type of aerial vehicle requires no assistance in recording an incident, and is capable of processing data obtained from various sources and passing a detailed report on the current state of events and developments to headquarters. These activities aid the decision-making process by providing specific information regarding the rescue needs, thus enabling the necessary numbers of rescue forces to be summoned (Berner and Chojnacki 2016, p. 54).

The rescue needs described in the preceding paragraph could provide the foundation for the development of an unmanned aircraft road accident rescue system. The system should include a local traffic and transport CCTV centre and operations centre, and above all specialist UAVs, whose objectives will be to:

- monitor and identify road incidents,

- supply medications and equipment to the site of the accident,

- transport victims to hospital.

In any case, the communication between the dispatcher located in the operations centre and the individuals on site at an accident is an absolute necessity to ensure the system functions properly, regardless of the condition of the victims. The classification of motor vehicle traffic crashes differentiates between a road collision and a road accident according to the health condition of the participants (Rożenek, Przasnyski and Gemza 2015, pp. 26-29); however, in either case, the health and life of victims is the absolute priority. Monitoring and identification of road traffic collisions and accidents should include both confirmation of the accident and determination of the exact crash site and evaluation of the victims' condition. Obtaining such information would require employing UAVs to patrol roads. The aircraft should be equipped with a set of cameras, and considering its potential involvement in a night event, night vision devices too (Berner and Chojnacki 2016, p. 8). Furthermore, the UAV should also be equipped with the data transmission technology, such as LINK-16, which allows real-time data transmission, also in the form of an image (Grenda 2011, pp. 300-312). 
Regarding the equipment of unmanned aircraft used by the services (e.g. the Police), we can distinguish systems fitted with optical sensors which perform monitoring activities in night scenarios. This type of UAV can also be used to search for traffic accident victims using thermal images obtained from infrared cameras. Thanks to thermal imaging cameras mounted on an airframe, a person in a difficult terrain may be immediately located (Levin et al. 2016).

Thermal imaging used in UAVs employs radiation below the visible light wavelength range and exploits the difference in ambient temperature and temperature emitted by a living organism to produce the image. With no additional lighting involved, this method enables the operator to spot people in bushes, vehicles, hidden under trees or buried in the ground. In thermal imaging cameras, the object is generated from the heat it emits. Therefore, the radiation range exhibits absolute independence of the environmental factors. To embrace the full capabilities of thermal imaging cameras, they could be used in systems coupled with visiblespectrum cameras (Antunes 2017).

While conducting a rescue operation, it is crucial to simultaneously observe the image from both the thermal and traditional camera. Parallel transmission facilitates the search process and increases the effectiveness of performed activities. The UAV-led activities do not have to be limited to mere observation of images, they can also involve the use of specialist software. These light and simultaneously very easily implemented platforms can instantly deliver high quality photos from both the air and ground (Berner and Chojnacki 2016, p. 54).

Specialist software plays an important role in the use of UAVs in road accident rescue. The Search and Rescue application is designed particularly for people search, and is ubiquitously used with UAVs. The software is used to determine the coordinates of a victim or any missing individual and automatically track them. The application also sends a message via email or SMS to the operations centre, thus aiding the search parties' efforts to reach the victim. The application accounts for different types of terrain to determine the shortest route, with the aim of improving the rate and effectiveness of the search (Berner and Chojnacki 2016, p. 54).

The flight routes can be adapted to any terrain: hills, mountains, trees or flat land. The software allows users to choose an automatic search mode, which operates 
on such variables as: altitude, field of view, the UAV battery life and probability of detection. Practical experience has shown that for a five-strong emergency team, an application requires an average of two hours to successfully find a victim in an area of one square kilometre. Computer analysis of images during search missions is typically aided by artificial intelligence methods.

In the HeyHelp application, the unmanned patrol platform conducts a real-time analysis of objects and, based on their size, their temperature and shape, and assesses whether the identified object is the true object of search activities. If the UAV recognises that a given organism is a human being, then both cameras, the thermal-imaging and the visible-spectrum one, are activated to record images (https://keyhelp.co/drone/). The images are subsequently sent to the coordinator of the rescue operation. This application is a solution used by, inter alia, armed forces and the fire service. A typical search team consists of an unmanned platform and a cooperating motor vehicle equipped with the Search Mission Manager software (Figure 1). The application stores images downloaded from the UAV and processes them prior to displaying them along with an interpretation of them (Waharte and Trigoni 2017, p. 1).

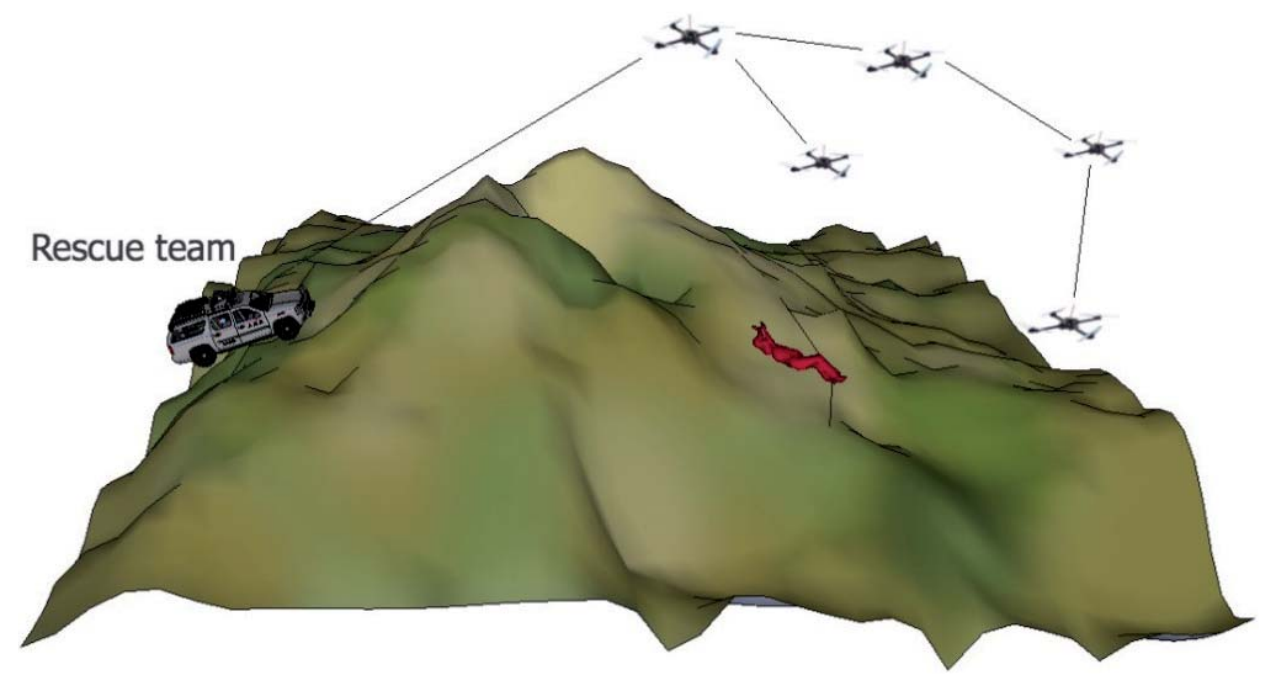

Figure 1. The search operation scheme based on Search Mission Manager software (Waharte and Trigoni 2017, p. 1) 
Statistics show that the most common cause of death among victims of accidents and road incidents is cardiac arrest: in certain cases, using a defibrillator could save lives. Already in 2013, researchers had attempted to develop an unmanned vehicle that would be able to transport a defibrillator. The result of their work, the Deficopter, develops a speed of up to $100 \mathrm{~km} / \mathrm{h}$, which increases the chances of the accident victim's survival from 8 to $80 \%$, by supplying medical assistance in the first 10 minutes after the occurrence of the event.

Another application of the UAV in the event of traffic incidents is the transport of victims to hospital. The first unmanned system of this type was created for military needs. The AirMule was constructed in Israel and is primarily designed to transport the wounded from the combat zone to safety. In addition, the system may be employed to carry supplies in urban areas. The aircraft is propelled by internal lift rotors located on the bottom of the chassis and two steerable fans at the rear of the construction for propulsion and direction. It can fly at a height of 3,600 metres and also at limited visibility and in strong winds of up to $93 \mathrm{~km} / \mathrm{h}$. Should rotor failure occur, a parachute is automatically deployed. The parachute rescue system is designed to bring the vehicle safely to the ground even from its maximum usable altitude (Atherton 2016, pp. 5-8).

\section{"Cricket" programme - protection of gas delivery networks}

One of the methods for addressing critical infrastructure security challenges with the help of the UAV has taken the form of Cricket programme. The project consists in developing and preparing the implementation of a system based on an innovative unmanned aircraft that would be responsible for periodic inspections of gas pipeline infrastructure. The vehicle's task is to evaluate the technical condition of the infrastructure, monitor the area in the immediate vicinity of the gas conduit and detect potential damage. Current solutions require the use of helicopters and involvement of specially trained pilots who analyse the changes in the gas conduit surroundings and identify the leak. The use of conventional manned aircraft is considerably more expensive and involves certain limitations, e.g. it is impossible to lower the flight if anomalies are detected on the ground. The planned solution is composed of an unmanned vehicle platform, logistics 
support enabling inspection in field conditions (including: the system for sending commands and receiving signals from the platform, the platform control system, the navigation system, and the transportation and technical support subsystems). The unmanned platform is additionally equipped with methane detection sensors as well as an IT system for storing and processing data from the inspection. This innovative unmanned platform will combine the characteristics of a rotorcraft and a classic aircraft that will enable vertical take-off and landing, hovering and economical flight. The compact size and the autonomous control of the developed UAV will enable it to approach the gas pipeline at a distance sufficient for accurate measurement, whereas the cost of the entire operation will be reduced.

The project fits in the framework of the National Smart Specialisation: Modern technologies of sourcing, processing and use of natural resources and the production of substitutes. Modern techniques and technologies for the safe and effective operation of gas infrastructure. The proposed - innovative type of dedicated UAV - is a solution for monitoring the condition of gas pipeline infrastructure, in addition it will be equipped with IT systems for data acquisition according to plans.

The solution will include such elements as: an unmanned vehicle capable of performing ordered tasks, logistics support enabling efficient and uninterrupted execution of tasks in field conditions (constituting a subsystem of a logistics support system that will consist of a control and navigation system and a transport and technical support subsystem). The platform will need to include indispensable structural components, i.e. measuring devices and an IT system for inspection data processing.

The developments in the field of additive manufacturing have allowed a reduction in the weight of joints and fasteners compared to traditional methods (milling) by approx. $75 \%$. Additive-manufactured fasteners exhibit sufficient durability, and what is more, this manufacturing method virtually eliminates post-production waste generation, hence reducing production costs.

Moreover, the energy consumption generated by the inspection of the supply network will be reduced, since at present, full-scale, manned helicopters are in service. Unmanned platforms, due to their significantly lower mass (the mass of the final product is expected not to exceed $150 \mathrm{~kg}$ - which is less than the total 
mass of the pilot and operator alone, not including the mass of the conventional manned helicopter itself), are notable for their several-fold lower energy use when covering the same distance, at the same time. In addition, since the method enables approaching the immediate environment of the gas pipeline, the annual inspection time interval will be extended as well. What is more, the application of methane detection sensors will undoubtedly increase the reliability of inspection, which at present relies solely on the organoleptic testing and experience of the helicopter crew.

The innovation of this new type of unmanned aircraft product predominantly consists in that it integrates the features of a rotorcraft and a fixed-wing aircraft. The desired features of the multi-rotor vehicle include: vertical take-off, hovering during flight and safe landing in virtually any conditions. However, with regard to drawbacks, this UAV shows high demand for energy, which furthermore can only be stored in batteries, which in turn means the vehicle has a limited range. Fixedwing aircraft are free from such limitations: they combine an extensive range with considerably higher cruising speeds. An aircraft that would integrate these features would become a perfect solution for monitoring gas supply networks. Currently, the inspection is conducted by highly specialised pilots who, working in teams with an observer, perform flight missions over gas supply networks in a conventional aircraft. Furthermore, gas leakage is most commonly diagnosed organoleptically, e.g. on the basis of a change in the colour of vegetation in the area of the spill - since methane causes it to acquire a yellow colour. Therefore, in Polish conditions, the detection is limited to the spring/summer period, owing to the snow cover. In winter scenarios, when the ground is frozen, the hazard from the severed gas pipeline may actually occur at a distance from the conduit. The frozen soil does not allow gas to escape into the atmosphere; therefore, it may travel through underground channels and find outlets where strict anti-explosive regulations do not apply (Pożar gazociagu... 2018).

Another method for the diagnosis of leakage of an underground gas pipeline is the observation of local collapses in the terrain, which typically evidence the leaching of the soil by the released gas. Similarly to the vegetation observation method, serious limitations are encountered in winter - when the frozen ground blocks the gas from leaking into the atmosphere, causing it to find its outlet further away from leakage site. The developed UAV is to be equipped 
with methane detection instrumentation, which combined with the small size and high-precision autonomous control system, will enable the gas pipeline to be approached at a sufficient distance to take measurements. Therefore, maintenance of gas conduits will be possible regardless of the weather - throughout the year, and, moreover, the entire operation will be considerably more economical. The proposed UAV has a novel design, which combines the features of a quadrocopter and a fixed-wing aircraft, merging the advantages of both solutions. Thanks to four rotors with a vertical axis of rotation, the vehicle takes off and lands in practically any place, and most importantly from the viewpoint of damage detection - the UAV is capable of hovering. On the other hand, by implementing a propeller with a horizontal axis of rotation, its flight parameters will match that of the fixedwing aircraft. Such UAVs are capable of covering much longer distances and developing higher cruising speeds compared to conventional multi-rotor aircraft vehicles. The platform will be equipped with technical instrumentation for leak detection and the optical recording system for the immediate vicinity of the gas supply network, control and navigation system and remote sensing; whereas the designated IT system will allow the processing of acquired data. In addition, UAVs equipped with cameras will be able to perform important functions in monitoring areas, detecting land collapses (leak detection) and taking aerial photographs, which will provide the basis for the creation of orthophotomaps ${ }^{1}$ of the terrain. In addition, it will be possible to perform land inspections for new investments.

1 Ortophotomap is a product of a differential rectification, which removes any distortions of the image that could appear as a result of the photo inclination or terrain height differences. A digital ortophotomap is a digital image of the terrain, constituting an ordered matrix of hue saturation values (0-255) ascribed to pixels and stored on a computer data carrier. The map is generated on a desired scale.

Digital images are obtained in two ways:

1. by digitising analogue images (typically involving a scanning aperture in a range of 15 to $30 \mu \mathrm{m}$, and special photogrammetric scanners, with geometric accuracy in the order of $\pm 1-2 \mu \mathrm{m}$.

2. by using special scanners and digital cameras, in which the image of the object is recorded not on the photographic material, but by means of a special sensor - in digital form (such a sensor may be a linear system or a matrix of CCD elements (Charge-Coupled Device).

The data providing the basis for the generation of orthophotomaps are: aerial photographs, elements of internal and external orientation of images, and the Digital Terrain Model (DTM). DTM is a discreet (expressed by points) numerical representation of the topographic elevation of the terrain surface with an interpolation algorithm, which enables the reproduction of its topography over a specific area. DTM is represented by points spread regularly or irregularly on the terrain surface and extended by points describing the morphological forms of the represented terrain (Digital Ortophotomap and Digital Terrain Model). 
Apart from the flying base, the platform includes the technical instrumentation for leakage detection and optical recording of the supply network vicinity, and the designated IT system will enable processing of the acquired data.

System operation will be relatively simple and will not require specialist knowledge from the operator. The UAV is transported to the place of measurement in a car equipped with IT equipment for data acquisition and analysis. Once airborne, the UAV, controlled by the programmed autopilot and the operator, will execute the route to the destined place of landing, which was optimised so as to maximally extend the flight without the need to refill the battery/fuel. Changing the power supply or refuelling will be carried out with ease in field conditions, following which the UAV will be ready to continue to conduct new measurements on the subsequent section of the supply network. If, during the flight, a methane leak or a change in vegetation colour is diagnosed as deviating from the norm, the UAV will initiate the hover move and the operator will take over the control. If no gas leak is detected, the UAV, depending on the remaining energy, will proceed to inspect the next section, or return to the operator to refuel/replace the batteries. The UAV operator will additionally be equipped with a manual laser Remote Methane Leak Detector - RMLD. Upon detection of leakage from the air, the operator will be able to drive to the place of rupture and perform a personal inspection of the threat in search of leakage.

According to the plan, the three built tester mock-ups will be scaled down to approx. 1:2 of the original design, however, their exact scale will depend on the optimisation of the tester weight at the constraint of maintaining the flight time. The primary reason for building the mock-ups is for the purpose of testing the correct operation of the entire system. The Maximum Take-off Weight (MTOW) of the testers will not exceed a range of 10-25 kg; therefore, they will not have to comply with certain aviation regulations, thus making the test flights considerably less complicated. Based on the data collected in the test flights, two full-size demonstrator prototypes will be built (1:1 scale); the prototypes will have the characteristics of the target product. The first step will be to prepare the necessary documentation so that the moulds can be manufactured by an external contractor. Having received the first components, a co-participator of the project will perform the strength tests, the results of which will be systematically implemented, and if need be, the project would be subjected to necessary modifications to meet the 
requirements of aviation regulations. In the final phase of the strength tests, the project leader will proceed to the integration and testing of systems in laboratory conditions, since the plan assumes the use of Commercial-Off-The-Shelf (COTS) elements. Therefore, such components as electric motors, a combustion engine (if hybrid-system solution is selected), control system, autopilot, batteries, regulators and propellers will be selected and purchased. Maximising the use of COTS elements will significantly reduce the operating costs of the UAV, and significantly facilitate future maintenance. In the next stage, the joint partner will start work on the dedicated IT system for acquisition and processing of data collected during the flights over the gas supply networks. Practically simultaneously, the leader will begin field tests of real models and then the demonstration prototypes. Field testing will be conducted in an open and wooded area. For the last six months, the UAV will be equipped with an IT system and the final results will be verified. Similarly to the previous stages, information exchange between consortium members will become crucial, and will affect the project success - it will take place via the website (with unlimited access granted solely to consortium members and general access to anyone interested in the project).

In addition, the UAV equipped with traditional photo-cameras operating in the visible light range and MOSP (Multi-Mission Optronic Stabilised Payload) thermal cameras operating in the infrared range - guided by the autopilot to specified GPS coordinates - will be able to perform important functions in monitoring the area, detecting surface collapses and offsets, and the creation of orthophotomaps - necessary for the allocation of new conduits.

The diagnostic flight will execute the pre-defined flight route based on the geographical coordinates of the pipeline. Regardless of the initially defined route of the carrier unit, the multiple-scope sensor module will also enable pre-defining the pipeline location. These systems, assisted by the inertial stabilisation function of the module frame, will ensure the control/directing of the optical axis of the module's optic-measurement devices directly on the defined pipeline route, regardless of any disturbances acting on the carrier unit (e.g. side wind pushing it off the planned flight route).

The project's success from the IT/measurement system perspective will be marked by the moment when the objective proof of capabilities is delivered, i.e.: measuring distance $1 \div 30 \mathrm{~m}$, measurement range $200-50000 \mathrm{ppm} * \mathrm{~m}$, and measurement resolution, of at least $0.6 \mathrm{~m}$ at a flight speed $25 \mathrm{~km} / \mathrm{h}$. 


\section{Conclusion}

The presented scientific considerations on the application of unmanned aerial vehicles focused on two directions of developments - both concerning the protection of the critical infrastructure elements, as the fundamental factor in the provision of high-level internal security. In the course of this analysis, it was resolved that it would be appropriate to collect and organise the current state of knowledge on unmanned aerial vehicles by presenting the relevant definitions and classifications, and thus creating a conceptual and semantic grid for future reference.

With regard to the first anticipated direction of development and application of UAVs - as a road accident rescue solution, it ought to be remarked that due to their extensive capabilities (the ability to monitor from the air, long flight time), these systems appear to be an extremely promising alternative. They can record traffic incidents, and may prove decisive in providing help to victims, which is extremely important in the event of a threat to human life. Harnessing the capabilities of UAV-based systems would require establishing a local monitoring centre equipped with a real-time data transmission system. Considering the aerial vehicles themselves, it was resolved that they should be equipped with optical sensors operating in the visible light and infrared wavelength range, as well as in night vision systems. The designed UAV system could be extended by a dedicated mobile application, which would support the system operation by aiding the location of injured individuals and optimising the search area.

Analysing the second of the UAV development paths, the provision of security to the state's critical infrastructure through protection of gas supply networks pointed to the native development concept - a programme under the codename "Cricket" (Polish: "Świerszcz") . It assumes the construction of a system enabling periodic inspections of the gas network infrastructure. An unmanned vehicle will be equipped with methane detection sensors, an IT system for data processing, and an autonomous control system. The vehicle's design will enable vertical takeoff and landing, hovering in the air, and inspection at an immediate distance to the gas conduit, which is expected to enhance the leakage detection rate. An additional supporting element will be the orthophotomaps module enabling charting the location of new gas pipelines. 


\section{References}

AAP-6, 2011. Słownik terminów $i$ definicji NATO zawierający wojskowe terminy $i$ ich definicje w NATO, Brussels.

Antunes J., 2017. Presenting the FLIR Duo at CES. New Thermal Imaging Devices for Your Drones.

Atherton K.D., 2016. Air Mule Hovercraft. Ambulance Files Autonomously, Rescue robocops January, 11.

Berner B. and Chojnacki J., 2016. Koncepcja wykorzystania dronów w ratownictwie drogowym. Bezpieczeństwo i Ekologia.

Berner B. and Chojnacki J., 2016. Wykorzystanie dronów do transportu towarów. Autobusy - Technika, Eksploatacja, Systemy Transportowe, 8.

Bielawski R., 2015. Wybrane zagadnienia z budowy statków powietrznych. Definicje, pojęcia i klasyfikacje, Akademia Obrony Narodowej, Warsaw.

Grenda B., 2011. The Air Force network centric management. Journal of KONBiN 3(19).

Janowczyk B., 2015. Reagowanie na zagrożenia związane z użyciem bezzałogowych statków powietrznych. Biuletyn kwartalnego Rządowego Centrum Bezpieczeństwa, 11.

Keyhelp: The Smart Help Drone, [online] https://www.indiegogo.com/projects/keyhelpthe-smart-help-drone\#/ [Accessed 25 Sep 2018].

Levin E., Zarnowski A, McCarty J.L., Bialas J., Banaszek A and Banaszek S., 2016. Feasibility study of inexpensive thermal sensors and small UAS deployment for living human detection in rescue missions application scenarios. The International Archives of the Photogrammetry, Remote Sensing and Spatial Information Sciences, Volume XLI-B8, XXIII ISPRS Congress, 12-19 July 2016, Prague, Czech Republic.

OrtofotomapacyfrowaiNumerycznyModel Terenu, 2017. Uniwersytet Rolniczyw Krakowie Wydział Inżynierii Środowiska i Geodezji Katedra Fotogrametrii i Teledetekcji.

Pożar gazociagu w Murowanej Goślinie: przyczyny zbada specjalna komisja, 2018 [online] https://poznan.onet.pl/pozar-gazociagu-w-murowanej-goslinie-przyczyny-zbadaspecjalna-komisja/gw9xb2k [Accessed 25 Sep 2018].

Przekwas A. and Jaroszuk R., 2009. Bezzałogowe statki powietrzne w rozpoznaniu wojskowym, Przegląd Wojsk Lądowych, 7.

Rożenek R., Przasnyski J. and Gemza M., 2015. Kwalifikacja zdarzeń drogowych oraz polecenia i sygnaty wydawane przez policjanta na miejscu zdarzenia drogowego, Centrum szkolenia Policji, Legionowo.

Sawicki P., 2012. Bezzałogowe aparaty latajace UAV $w$ fotogrametrii i teledetekcji - stan obecny i kierunki rozwoju. Archiwum Fotogrametrii, Kartografii i Teledetekcji, 23.

Ustawa z dnia 26 kwietnia 2007 r. o zarządzaniu kryzysowym (DzU z 2007 r. Nr 89, poz. 590, art. 3). 
Waharte S. and Trigoni N., 2017. Supporting Search and Rescue Operations with UAVs, University of Oxford, Computing Laboratory, Oxford, United Kingdom.

Zalewski P., 2001. Klasyfikacja UAV: zasięg, pułap i dtugotrwałość na podstawie - system klasyfikacji UAV wg. standardów NATO, Przegląd Wojsk Lotniczych i Obrony Powietrznej, 12. 